\title{
The Subject of Male Hysteria and Male Masochism in David Fincher's Fight Club
}

\author{
Paraskevi Chourdaki \\ PhD Candidate, Dept. of Primary Education \\ University of Athens, 13A Navarinou \\ 10680 Greece
}

\begin{abstract}
The current research paper explores the various themes found in David Fincher's 1999 film Fight Club with a focus upon the subject of male hysteria and male masochism as shown through the main character's point of view. The fear of metaphorical emasculation in the contemporary materialistic and capitalistic society, the identity crisis as well as the notion of physical violence as a means against all threats to masculinity are thoroughly discussed and interrelated. What this paper also attempts to look at is the duality of self, gender and sexuality stereotypes and the delusional expectations the modern individual has acquired which lead the latter to total paranoia and inner/outer chaos; all seen through the eyes of the film's director and protagonist.
\end{abstract}

Key words: cinema; identity; stereotypes; masculinity; sexuality; hysteria; masochism

David Fincher's Fight Club, based on Palahniuk's novel, is considered a milestone in the World of Cinema due to its multi-dimensional nature and wide variety of themes. There is no doubt, though, that, out of all the subjects with which Fight Club deals, male hysteria and male masochism stand out. These two are embodied and represented in different ways by the main protagonist of the book/film, the Narrator or else Jack; "[a]n insomniac who leafs through Ikea catalogues rather than porn, [who] finally achieves sleep through pretending to have serious illnesses and attending support groups to reach tearful catharsis" according to Windrum [306]. Jack, supported by his alter-ego, Tyler Durden, constitutes the ultimate symbol of what is called "masculinity in crisis" and, thus, is in constant search of his real identity and sexuality.

In a society where the shadow of capitalism, materialism and consumption threatens not only the freedom and independence of the modern individual but also the very existence of the nation, "[...] the white male rebel must revolt against a dominant culture that has ostensibly pushed his masculinity to the margins." (Ta 269). According to Nicola Rehling, the man of the 90's has victimized himself by having become passive in his role as a producer and obtained that of a consumer, as depicted in films such as Disclosure and The Full Monty [70], while simultaneously the roles of the sexes have dramatically changed. Women start building careers rather than households while becoming more confident concerning their role in society and male-independent. This is something that caused great anxiety among the male population combined with the rejection the latter felt from the society due to their previously-stated passiveness as well as their immersion in meaningless jobs which offered them no pleasure at all. Also, the so-called "routine of everyday life" gave birth to the one-dimensional man who, in order to gain back his lost manhood, seeks ways of feeling alive again through pain and suffering. He tries to embrace other people's pain as if it is his, with the result that the melancholic and castrated from the feminized society male is finally led to sadomasochistic trends. 
All of the above is taken into account when examining the overall behavior of Jack, who, along with Tyler, "[...] create[s] an underground bare-knuckles club where men can beat their sufferings out of each other." (Giroux and Szeman 97); in an attempt to fill the tremendous gap of the absent paternal figure, one might add. Tyler himself argues that "we are a generation of men raised by women and I'm beginning to wonder whether another woman is really the answer to what we need" emphasizing the abandonment by his own father and the influence it had on the formation of his personality. In the film, as Rehling has observed, "[v]iolence is therefore valorized because it is posited as one of the few characteristics to which men can still lay exclusive claim." [77]. After each fight, the protagonist as well as the other members of the club feel extremely alive and are rewarded with scars and bruises that prove not only their masculinity but also their heterosexuality.

As Gronstad underlines, Jack actually enjoys physical pain and sees it as a way of freeing himself and overcoming his masculinity [16]. His masochistic nature is vividly shown in one of the most gruesome scenes of the film, that of Tyler kissing Jack's hand and then pouring lye onto it (this is, in fact, a self-abuse scene since Tyler is Jack's alter-ego), so as to highlight the fact that he likes being God's unwanted child and he would do anything to maintain this position. Quiney is right in his view that the whole ritual in this scene "[...] serves both as rite of initiation into a traditional "masculinity" marked by the endurance of physical pain, and also as a gateway to "real" experience." [340]. On a second level of analysis, one might find hints of homoeroticism, as well, though this will be further discussed later on.

In the domain of male masochism of the film, Gronstad argues that acts of abnormal alterations of the body must be examined: the character of Robert Paulson/Bob is the most significant example, since he has grown female breasts after given steroids, the victims of cancer in other support groups have weak bodies as well as symptoms such as total loss of hair, Jack/Tyler uses fat from liposuction clinics to make soap (reference to Holocaust), Jack's hand burned by lye and the self-shooting of Jack through the head.

Even though violence is highlighted in the film as being the savior of the male from the feminized and "faceless world of corporate America" (Ta 266), Fincher parodies it with the scene in which the Narrator beats himself up in his boss's office when the latter refuses to get in a fight with him. One cannot agree more with Ta in her claim that "[...] as Jack attempts to lash out against his boss, the corporations, and commodity culture, he ends up attacking himself." [275]; something that indicates the state of self-delusion he is in, in the sense that, although he believes he can punch capitalism in the face (here represented by his own boss), he only hurts himself. Apart from this element of comic in this scene, the whole movie promotes violence as a powerful way of resurrecting oneself.

The issue of masochism is interlinked with that of male hysteria, one being the outcome of the other. The repression of male aggression has led to the instability of male identity and to the creation of - according to Freud - "[...] a masochistic phantasy in men [...] [to] place the male in a 'characteristically female situation."' (Creed 120). This becomes evident in other films, as well, from the horror genre: e.g. The Silence of the Lambs, in which the schizophrenic killer, Buffalo Bill, aspires to become a woman by flaying his female victims and wearing their skin, with a view to reach a high level of femininity, which he believes will give him superiority (Creed 126).

Hysteria, as a mental disease, was thought to be primarily characteristic of female patients and was considered a form of physical expression of repressed opposition to the patriarchal society 
(Rehling 69). However, as mentioned before, male hysteria exists and is represented in various ways in Fight Club.

To begin with, the protagonist has ended up being an Ikea slave obsessed with furniture and modern equipment, a fact that points to the direction of his emasculation since the traditional male figure of the past used to read porn, was preoccupied with his job and left all the rest to the woman of the house, unlike Jack. In order to get rid of his insomnia, he turns to a group of men with testicular cancer called "Remaining Men Together" who has in common with him the loss of masculinity (though the massive difference here is that Jack's "loss" is not somatic). This kind of psychotic fear of castration that Jack undergoes drives him crazy, even after the creation of his other half, Tyler, who, oddly enough, "[...] splices shots of penises into family films.", as one of his occupations, and in a figurative manner, as Ta emphasizes, "[...] [he] cuts off his own penis and inserts it into the family unit as a means of reasserting patriarchal authority in an otherwise matriarchal society." [270]. Additionally, when Jack is encouraged by another support group to find his power animal, in order to find peace of mind, he mentally enters a cave where he encounters a penguin; a bird who cannot fly, thus, a symbol of his own entrapment (Gronstad 10) which is replaced later in the film by the entity of Marla Singer.

Furthermore, Jack's/Tyler's emasculative fear is obvious when Durden enters Marla's house and feels threatened, in a way, by her huge dildo (Ta 270). It becomes quite clear, then, that the symbol of phallus is transparent throughout the film as a constant reminder of the male power that is now in danger in the modern society. The first scene of the film, which is also one of the last, shows Tyler holding a gun in Jack's mouth threatening him, a scene translated by some critics as highly homoerotic, since the gun itself is another symbol of the phallus. In addition, even the musical soundtrack of the film serves as a representation of male hysteria, with the song by The Pixies "Where is My Mind?" playing in the final scene, along with the phallic image of the skyscrapers falling down (Windrum 314).

Rehling suggests that the double personality of the hero itself serves as the main symptom simultaneously a result - of his hysteria and paranoia [78] and is, also, responsible for the suppression of his homoerotic tendencies. That is why Tyler emerges from Jack's imagination and becomes not only, as Quiney puts it, "[...] a fetishized object of desire [...]" [341] for him but also a kind of replacement in his weird relationship with Marla. Hysteria takes control of Jack's personality, with the homoerotic atmosphere heavily highlighted, in the brutal scene of Jack fighting against Angel Face (Jared Leto), whom he disfigures in the face, because of the latter's beauty that "activated" homosexual feelings in the Narrator (Rehling 72). Also, the previously mentioned kiss of Tyler on the hand of Jack, before he burns it with acid, can be interpreted as homoerotic gesture, with a first glance, and as narcissism, after a second viewing supported by the knowledge that Tyler is a fragment of Jack's imagination.

Obviously, the ambiguous sexual identity of the protagonist accounts for his creation of his alter-ego, in the sense that Tyler, being the exact opposite of Jack, is able to sleep with Marla without any emotional attachment on his part. Marla becomes something of a verification of his masculinity, although only Tyler is presented as her lover and not Jack. Tyler embodies everything Jack is not: macho, independent of materialistic values and fearless of the world, and he knows it (Tyler claims "I look like you want to look; I fuck like you want to fuck"). He is the ideal male for Jack, as "[the male protagonist's] image is dependent upon narcissistic phantasies, phantasies of the "more perfect, more complete, more powerful ideal ego'" (Neale 279). But is this enough, in a society full of copies? According to Jack himself, "everything is a copy of a copy of a copy", including Tyler (Ta 272). 
Marla plays a very important role in Jack's/Tyler's life even though he tries to have a superficial and strictly sexual relationship with her. When Project Mayhem - a paramilitary group of "space monkeys", as Tyler calls them, on the verge of terrorism - comes to life, Tyler sets the goal to destroy corporate companies, banks and everything that characterizes capitalistic America of the 90's. When this Project is finally revealed, though, Jack finds Marla and tries to convince her to get away because she is in danger due to him and his actions. On the one hand, Jack desires her but on the other hand he has formed in his mind a relationship with Tyler corresponding to that of Ozzie and Harriet.

Back to Project Mayhem, which will both "bring on a cultural ice age and a prematurely induced dark age", as Tyler hopes, and will "[...] fill the paternal vacuum historically occupied by the state, the "Fatherland."' (Quiney 335). However, this whole scheme, which is an extension of the idea of Fight Club in the first place, fails to fulfill the expectations and dreams of its members due to the fact that, as Ta correctly is led to believe, "[...] these individuals seek relief from an oppressive capitalistic order through means that are equally conforming and repressive." [267]. David Fincher borrows elements from satire in order to make his point, as regards the system, and shows Project Mayhem as a big joke. In this neo-Nazi environment full of alienated men who think they will change the world, Bob - a former body builder with "bitch tits", as Jack sees it, whom he meets in "Remaining Men Together" - is killed during an operation, making Jack want to shut down the organization altogether. Soft Jack attacks Tough Tyler again.

Summarizing, as Rehling supports "although the film flirts with controversial ideas such as nihilism, anarchy, fascism, homoerotic desire, male masochism, and fantasies of patriarchal restoration, and also delights in pushing the limits of "good taste" and political correctness (not even cancer victims are immune from its caustic humor), it can also deflect criticism by claiming that Tyler is just a figment of the insane narrator's imagination, who is finally expelled when the narrator, albeit in a tongue-in-cheek manner, gains "maturity."” [68].

Even though it was not a box-office hit, when came out on DVD, Fight Club became an instant success dividing film critics and audiences. "[T]he film's screening of remasculinization through violence might have a profoundly disturbing effect on the young men at whom the film was marketed." (Rehling 68), according to some reviewers who turned against the movie and its director. Even if some of these views have realistic tones, there is no doubt that Fight Club's uniqueness prevails and takes the spectator on a journey of illusion and hysterical pleasure.

\section{References}

Creed, Barbara. "Dark Desires. Male Masochism in the Horror Film”. Screening the Male. Exploring Masculinities in Hollywood Cinema. Eds. Steven Cohan and Ina Rae Hark. New York: Routledge, 1993. 118-133. Print.

Giroux, Henry A. and Imre Szeman. "Ikea Boy Fights Back: Fight Club, Consumerism, and the Political Limits of Nineties Cinema." The End of Cinema As We Know It: American Film in the Nineties. Ed. Jon Lewis. London: Pluto Press, 2001. 95-104. Print.

Gronstad, Asbjorn. "One-Dimensional Men: Fight Club and the Poetics of the Body." Film Criticism 27.1 (2003): 113 . Print.

Neale, Steve. "Masculinity as Spectacle." The Sexual Subject: A Screen Reader in Sexuality. Ed. Many Merck. London: Routledge, 1992. 277-87. Print.

Quiney, Ruth. "Mr. Xerox", the Domestic Terrorist, and the Victim-Citizen: Masculine and National Anxiety in Fight Club and Anti-Terror Law." Law and Literature 19 (2007): 327-354. JSTOR. Web. 4 April 2012.

Rehling, Nicola. Extra-Ordinary Men: White Heterosexual Masculinity and Contemporary Popular Cinema. Lanham, MA: Lexington, 2009. Print. 
Ta, Lynn M. "Hurt So Good: Fight Club, Masculine Violence and the Crisis of Capitalism." The Journal of American Culture 23.9 (2006): 265-77. Web. 2 June 2009.

Windrum, Ken. "Fight Club and the Political (Im)potence of Consumer Era Revolt." New Hollywood Violence. Ed. Jay Schneider. Manchester: Manchester University Press, 2004. 304-317. Print. 